\title{
Removal of Heavy Metal from Waste Water Using Activated Carbon from Rice Husk
}

\author{
Rintong I. Babatunde* and Abdulrauf A. Ibrahim \\ *Department of Civil Engineering, Kaduna polytechnic, Kaduna. Nigeria. \\ Department of Mechanical Engineering, Kaduna Polytechnic, Kaduna, Nigeria
}

\begin{abstract}
Adsorption of heavy metals is a new technology for the treatment of wastewater containing different types of selected heavy metals. This study investigated the adsorption capacities of Pb and Cd onto ARHC and URHC made out of rice husks, available as agriculture waste. The effect of various parameters such as $\mathrm{pH}$, adsorbent dose, adsorbent concentration, and contact time on the removal of $\mathrm{Pb}$ and $\mathrm{Cd}$ by $\mathrm{ARHC}$ and URHC were also examined. It was discovered that adsorption capacity decreases with an increase in $\mathrm{pH}$ solution this so because the available $\mathrm{Pb}$ and $\mathrm{Cd}$ molecules are not able to cover all the exchangeable sites on the biosorbent. The equilibrium data fitted with Langmuir and Freundlich isotherm models, but best fitted with the Langmuir isotherm model. The adsorption kinetics for this study was best described by the pseudo-second-order kinetics.
\end{abstract}

Keywords: Adsorption, Activated carbon, Environmental Pollution, Heavy metals Rice Husk.

\subsection{INTRODUCTION}

Heavy metal refers to any metal or metalloid element that has a relatively high density ranging from $3.5 \mathrm{~g} / \mathrm{cm}^{3}$ or more and is toxic or poisonous at low concentration. Water pollution due to the presence of heavy metals has become a major source of concern to the general public because of their toxicity effect in the discharging environment as well as on the overall efficiency of the biological treatment plant [1] Several episode of heavy metal contamination in aquatic environment have increased the awareness about heavy metal toxicity. Among these are the Minamata disease due to mercury poisoning and Itai -Itai disease in Japan due to cadmium which is all well-known [2] More recently cases of Lead $\mathrm{Pb}^{2+}$ poisoning were reported in Zamfara State, Nigeria; which resulted in the death of several people and animals as a result of Lead contamination of water bodies [3]. Nowadays, the industrial and domestic wastewater if not properly managed will be responsible for severe damage to the environment and adversely affecting the health of people [4]

\subsection{LITERATURE REVIEW}

Water pollution is the introduction into fresh or ocean waters of chemical, physical, or biological materials that degrade the quality of the water and affect the beings living in it. It is the second most important environmental issue next to air pollution [5]. This process ranges from simple addition of dissolved solids to discharge of the most insidious and persistent toxic pollutants (such as pesticides, heavy metals, and none degradable, bio-accumulative, chemical compounds). Pollution of the water bodies disturbs the ecosystem as a whole. According to [5] polluted water is not only unsafe for drinking and other consumption purposes, but it is also unsuitable for agricultural usages. The effects of water pollution are detrimental to human beings, plants, animals, fish and birds [6]

The current world economic paradigms, sustainable socioeconomic development of every community depends much on the sustainability of the available water resources.Adsorption is widely used as an effective physical and chemical methods of separation in order to eliminate or lowering the concentration of wide range of dissolved pollutants (Organic and inorganic) in an effluent. It is big news that activated carbon (AC) is a well-known adsorbent that can be used efficiently for removal of a broad spectrum of pollutants from air, soil and water [7]. Adsorbents are usually porous solids, and adsorption occurs mainly on the pore walls inside particles. Examples are activated carbon (adsorbs mainly organics), silica gel and activated alumina (adsorb moisture), zeolites and molecular sieves and synthetic resins. Among them, AC is more efficient adsorbent for elimination of many pollutants (organic, inorganic, and biological) of concern in water and wastewater treatment [8]. In the recent years, it has been increasingly used for the prevention of environmental pollution and antipollution laws have increased the sales of $\mathrm{AC}$ for control of air and water pollution [9]. AC is a broad-spectrum agent that effectively removes toxic and bio-refractive substances 
such as insecticides, herbicides, chlorinated hydrocarbons, heavy metal ions, pharmaceuticals and phenols, typically present in many water supplies [10][11] Applications of Activated Carbon are enormous. It is use for gasoline vapor emission control canisters in automobile.

\subsection{METHODOLOGY}

Chemicals and reagents used for this work are of an analytical grade, and they include;

Sodium hydroxide $(\mathrm{NaOH})$, hydrochloric acid $(\mathrm{HCl}) \mathrm{BDH}$ chemicals limited England, ammonium chloride $\left(\mathrm{NH}_{4} \mathrm{CL}_{3}\right), \mathrm{Burgoyne}$ and co India. The instrument/apparatuses include, Analytical weighing balance (Adam Equipment Co, Ltd US), muffle furnace , mechanical shaker, Atomic absorption spectrophotometer (AAS),pH meter(HI96107 model),beakers, 250 mL Erlenmeyer flask, volumetric flask, measuring cylinder, pistil and mortar, sieve, whatsman filter paper, burette, pipette, pipette filler, conical flask, cuvet, $50 \mathrm{~mL}$ volumetric flask, test tubes, test tube rack, wash bottles, and sample bottles.

\subsection{Collection of Precursor and Preparation of Adsorbents}

Rice husk were collected from a rice mill in station market Barnawa in Kaduna state northwest Nigeria located on Latitude $11^{\circ} 10^{\prime} \mathrm{N}$ and longitude $7^{\circ} 38^{\prime} \mathrm{E}$. The rice husk was washed with tap water followed by distilled water to remove dirt and air-dried. A portion of the air-dried rice husk was pyrolysed in a muffle furnace at $350^{\circ} \mathrm{C}$ for $30 \mathrm{~min}$, pulverized and sieved to give unactivated rice husk carbon (URHC). A portion of the rice husk was steeped in ammonium chloride solution overnight for chemical activation. The slurry was filtered and the residue washed repeatedly with distilled water, followed by air-drying. It was also pyrolysed in a muffle furnace at $350{ }^{\circ} \mathrm{C}$ for $30 \mathrm{~min}$, pulverized and sieved to give activated rice husk adsorbent (ARHC), [11]

\subsection{Adsorption Experiments}

\subsubsection{Preparation of laboratory stock solution (adsorbate)}

\subsubsection{Lead Stock Solution $(\mathrm{mg} / \mathrm{L})$}

A (1.5980g) portion of Lead Nitrate $\mathrm{Pb}\left(\mathrm{NO}_{3}\right)_{2}$ was weighed using an analytical balance and dissolved in $250 \mathrm{~cm}^{3}$ conical flask with deionized water. The solution was transferred to a $1000 \mathrm{~cm}^{3}$ volumetric flask and made up to the mark with deionized water and will be clearly labeled as the $1000 \mathrm{mg} / \mathrm{L}$ Lead standard solution.[12]

\subsubsection{Cadmium Stock Solution $(\mathrm{mg} / \mathrm{L})$}

A $2.8 \mathrm{~g}$ of Cadmium nitrate tetra hydrate $\left(\mathrm{Cd}\left(\mathrm{NO}_{3}\right)_{2} \cdot 4\left(\mathrm{H}_{2} \mathrm{O}\right)\right.$ was weighed using an analytical balance and dissolved in $250 \mathrm{~cm}^{3}$ conical flask with deionized water. The solution was transferred to a $1000 \mathrm{~cm}^{3}$ volumetric flask and made up to the mark with deionized water and will be clearly labeled as the $1000 \mathrm{mg} / \mathrm{L} \mathrm{Cadmium} \mathrm{standard} \mathrm{solution.}$

\subsubsection{Effect of initial $\mathrm{Pb}$ and $\mathrm{Cd} \mathrm{pH}$ on removal}

Separate 50-mLaliquots of a $100-\mathrm{mgL}^{-1} \mathrm{~Pb}$ and $\mathrm{Cd}$ solution, were adjusted with $\mathrm{NaOH}$ and $\mathrm{HCl}$ at $\mathrm{pH} 3,5,7,9$ and 11 and contacted with $0.5 \mathrm{~g}$ of $\mathrm{ARHC}$ and URHC. The flasks were agitated for $90 \mathrm{~min}$ on a shaker, the mixture was filtered and the residual metal ion concentration measured with the aid of an Atomic absorption spectrophotometer (AAS). This procedure was repeated thrice and average taken.[12][13]

\subsubsection{Effect of adsorbent dosage on $\mathrm{Pb}$ and $\mathrm{Cd}$ removal}

Separate 50-mLaliquots of a $100-\mathrm{mgL}^{-1} \mathrm{~Pb}$ and $\mathrm{Cd}$ solution, was contacted with $0.5,1,1.5,2$ and $2.5 \mathrm{~g}$ of ARHC and URHC. The flasks were agitated on a shaker for $90 \mathrm{~min}$. the mixture was filtered and the residual metal ion concentration measured with the aid of an Atomic absorption spectrophotometer (AAS). This procedure was repeated thrice and average taken[12][13].

\subsubsection{Effect of concentration on $\mathrm{Pb}$ and $\mathrm{Cd}$ removal}

Separate 50-mLaliquots of 20, 40, 60, 80 and $100 \mathrm{mgL}^{-1} \mathrm{~Pb}$ and Cd solution was contacted with $0.5 \mathrm{~g}$ of ARHC and URHC at room temperature. The flasks were agitated on a shaker for $90 \mathrm{~min}$. the mixture was filtered and the residual metal ion concentration measured with the aid of an Atomic absorption spectrophotometer (AAS). This procedure was repeated thrice and average taken.[12-13]

\subsubsection{Effect of contact time on $\mathrm{Pb}$ and $\mathrm{Cd}$ removal}


Separate 50-mLaliquots of a $100 \mathrm{mgL}^{-1} \mathrm{~Pb}$ and $\mathrm{Cd}$ solution will be contacted with $0.5 \mathrm{~g}$ of ARHC and URHC for10,20,30,60,90 and $120 \mathrm{~min}$ at room temperature. The flasks were agitated on a shaker, after the elapse of 10 to 120 min. the mixture was filtered and the residual metal ion concentration measured with the aid of an Atomic absorption spectrophotometer (AAS)

\subsection{RESULTS}

\section{Result showing Adsorption Capacities}

\subsection{Equilibrium Adsorption Capacities}

Equilibrium data from adsorption experiments are usually presented in the form of an isotherm, which graphically displays the ratio of sorbed to non-sorbed solute per unit mass of the adsorbent at room temperature (Figures 5 - 8), display the isotherms for the aqueous phase adsorption of metal ions onto the different Rice husk adsorbents (ARHC) and (URHC) Metal ions removal efficiencies were calculated from the equilibrium adsorption data as the percent of lead and cadmium removed with the aid of Equation( 8)

$\mathrm{E}(\%)=\left(\frac{C_{o}-C_{e}}{C_{o}}\right) x 100$

Where $C_{\mathrm{o}}$ and $C_{e}$ are the initial and residual (equilibrium) $\mathrm{Pb}$ and $\mathrm{Cd}$ concentrations (mgL).

In the operating range of initial phenol concentrations $\left(20 \leq C_{e} \leq 100 \mathrm{mg} \mathrm{L}^{-1}\right)$, corresponding equilibrium adsorption capacities, $Q_{e}$ $\left(\mathrm{mg} \mathrm{g}^{-1}\right)$ for (ARHC) and (URHC), respectively at room temperature thus:- $\mathrm{ARHC} \mathrm{Pb;}\left(1.609 \leq Q_{e} \leq 5.649\right)$ and $\mathrm{Cd}$; $\left(1.579 \leq Q_{e} \leq\right.$ 4.914) and $\mathrm{URHC} \mathrm{Pb} ;\left(1.56 \leq Q_{e} \leq 5.14\right)$ and $\mathrm{Cd} ;\left(1.499 \leq Q_{e} \leq 4.929\right)$. The range of adsorption efficiencies across range investigated were: ARHC $(56.47 \leq E(\%) \leq 80.44)$ and URHC $(49.14 \leq E(\%) \leq 78.93)$. Comparatively, it seemed that the capabilities of the adsorbents to remove $\mathrm{Pb}$ and $\mathrm{Cd}$ varied as ARHC $>\mathrm{URHC}$ in terms of percent removal portraying activated rice husk adsorbent (ARHC) as a more potent of the experimental adsorbents. The isotherm profiles are also noteworthy because they can provide information regarding the nature and intensity of sorption for a particular adsorbate-adsorbent system (Hajiiraet al., 2018. Guan-quian et al., 2012).

\subsection{Adsorption isotherm models}

Isothermal data for the adsorption of metal ions from aqueous phase onto the different adsorbents Rice husk carbon were fitted into the linearized forms of the Langmuir Equation (1) and Freundlich Equation (3) isotherms.

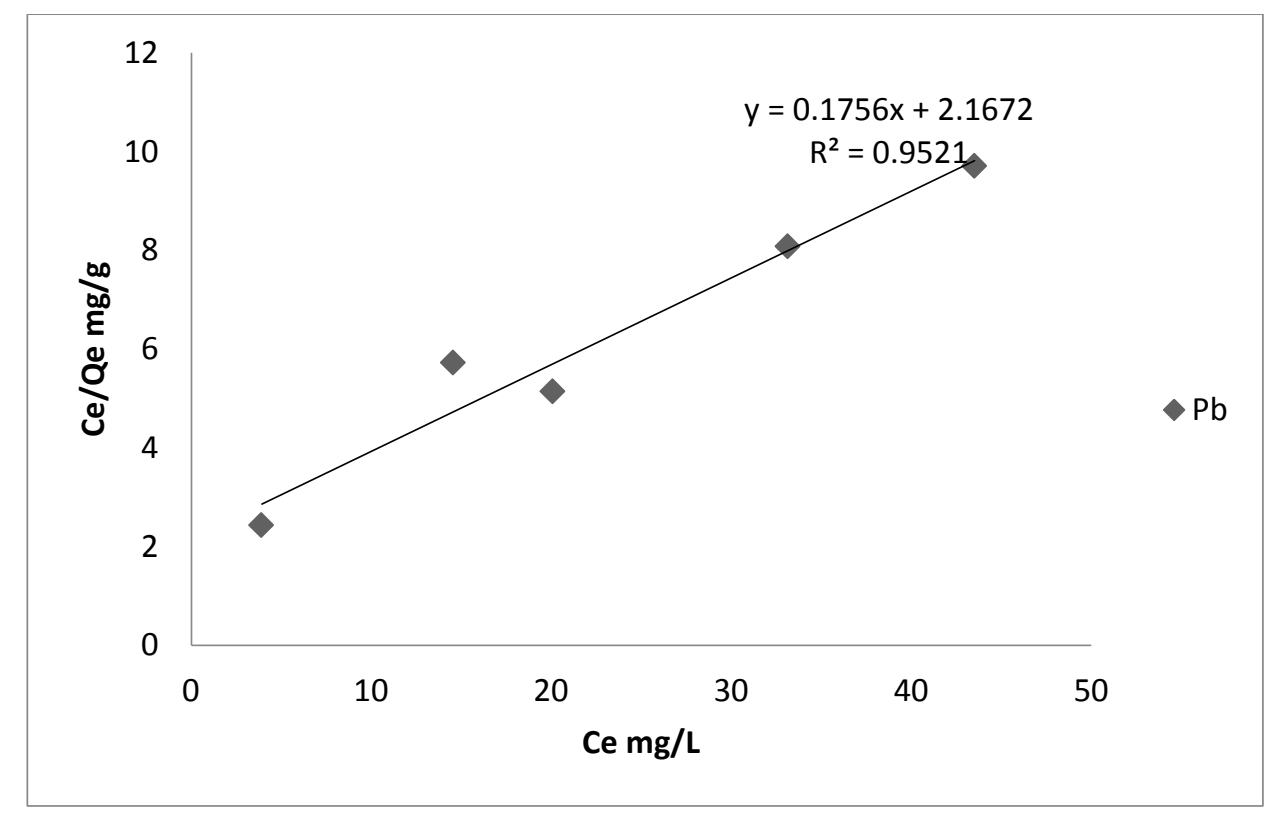

Figure 1. Linearized Langmuir Isothermsfor Adsorption of Pb onto Activated Rice husk adsorbent $(\mathrm{dose}=0.5-\mathrm{g} / 50 \mathrm{~mL})$ 
International Journal of Advances in Scientific Research and Engineering (ijasre), Vol 6 (2), February-2020

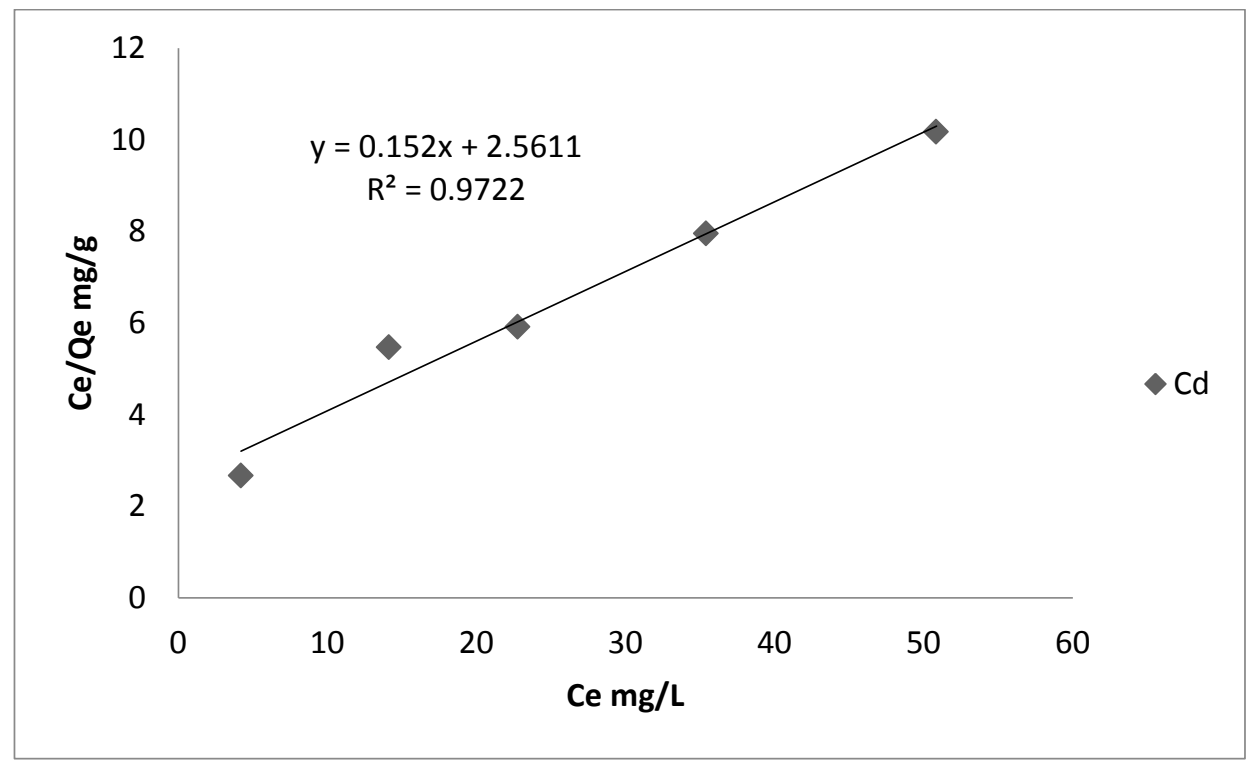

Figure 2. Linearized Langmuir Isotherms for Adsorption of Cd onto Activated Rice husk adsorbent $(\mathrm{dose}=\mathbf{0 . 5}-\mathrm{g} / \mathbf{5 0} \mathrm{mL})$

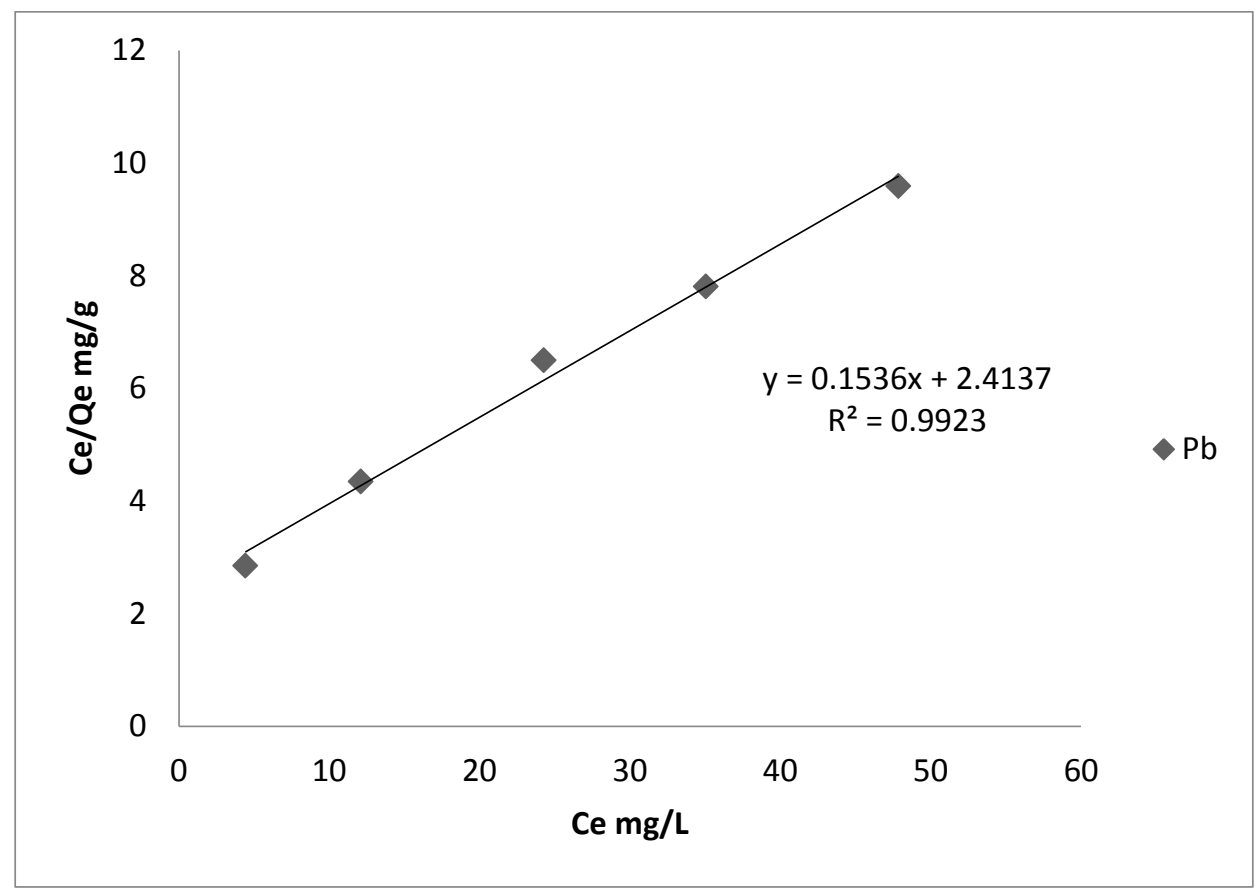

Figure 3. Linearized Langmuir Isotherms for Adsorption of Pb onto Unactivated Rice husk adsorbent $($ dose $=0.5$ $\mathrm{g} / \mathbf{5 0} \mathbf{~ m L}$ ) 
International Journal of Advances in Scientific Research and Engineering (ijasre), Vol 6 (2), February-2020

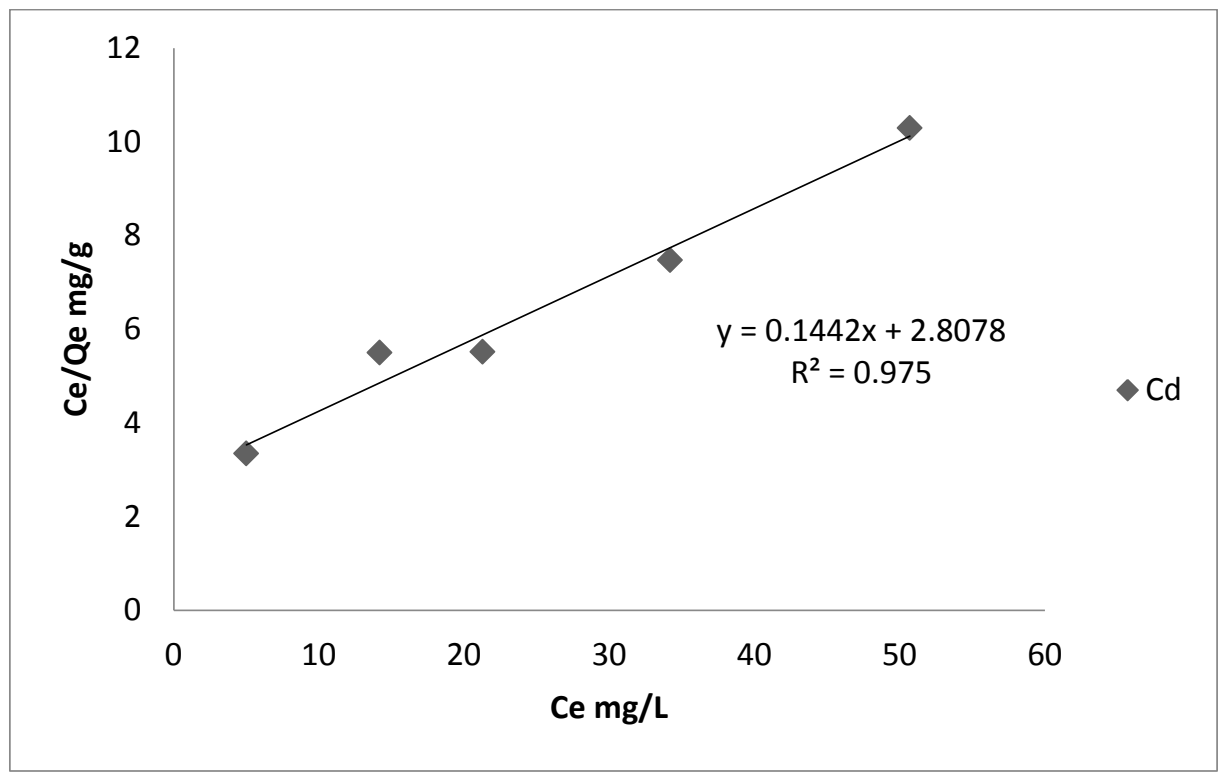

Figure 4. Linearized Langmuir Isotherms for Adsorption of Cd onto Unactivated Rice husk adsorbent $(\mathrm{dose}=\mathbf{0 . 5}-\mathrm{g} / \mathbf{5 0}$ $\mathbf{m L})$

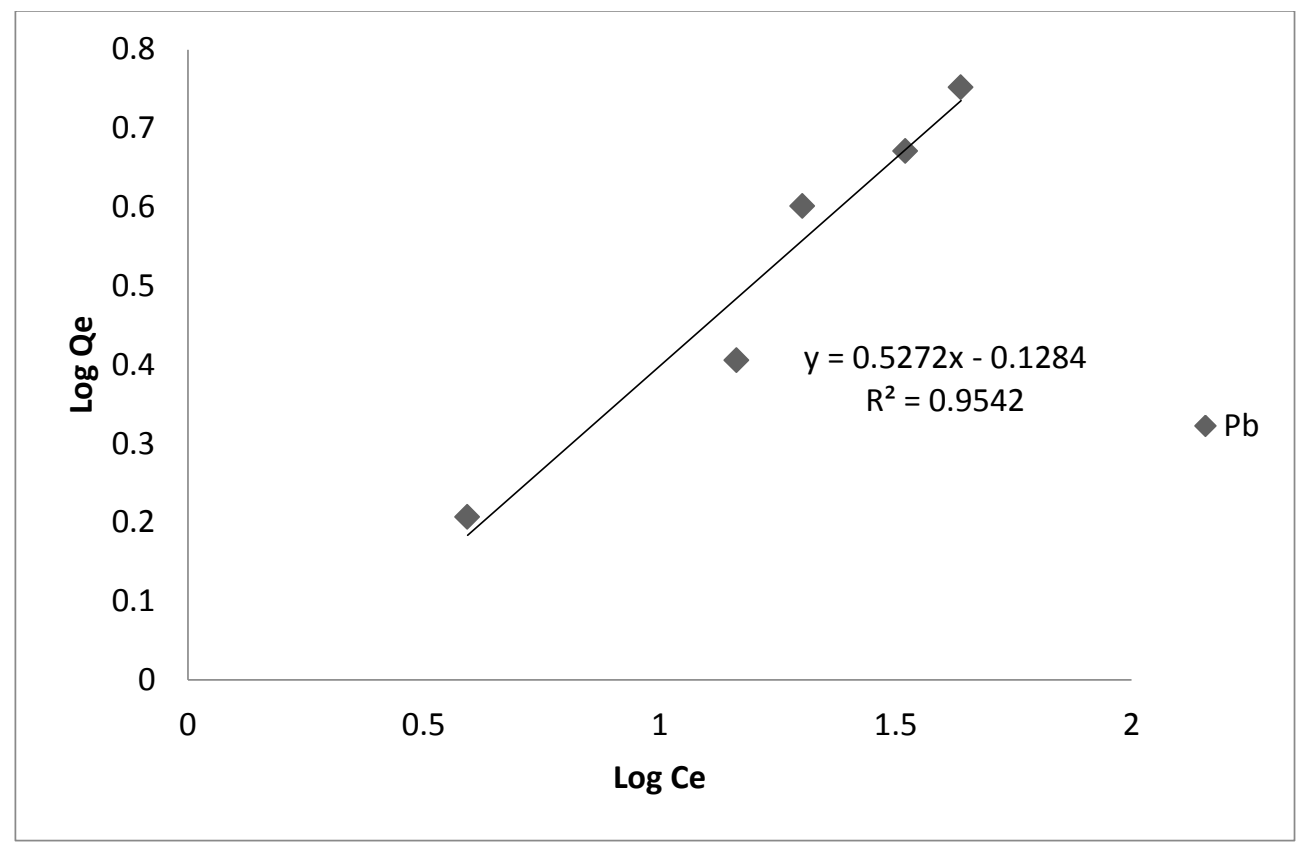

Figure 5. Linearized Freundlich Isotherms for Adsorption of Pb onto Activated Rice husk adsorbent $($ dose $=0.5-\mathrm{g} / 50 \mathrm{~mL})$ 
International Journal of Advances in Scientific Research and Engineering (ijasre), Vol 6 (2), February-2020

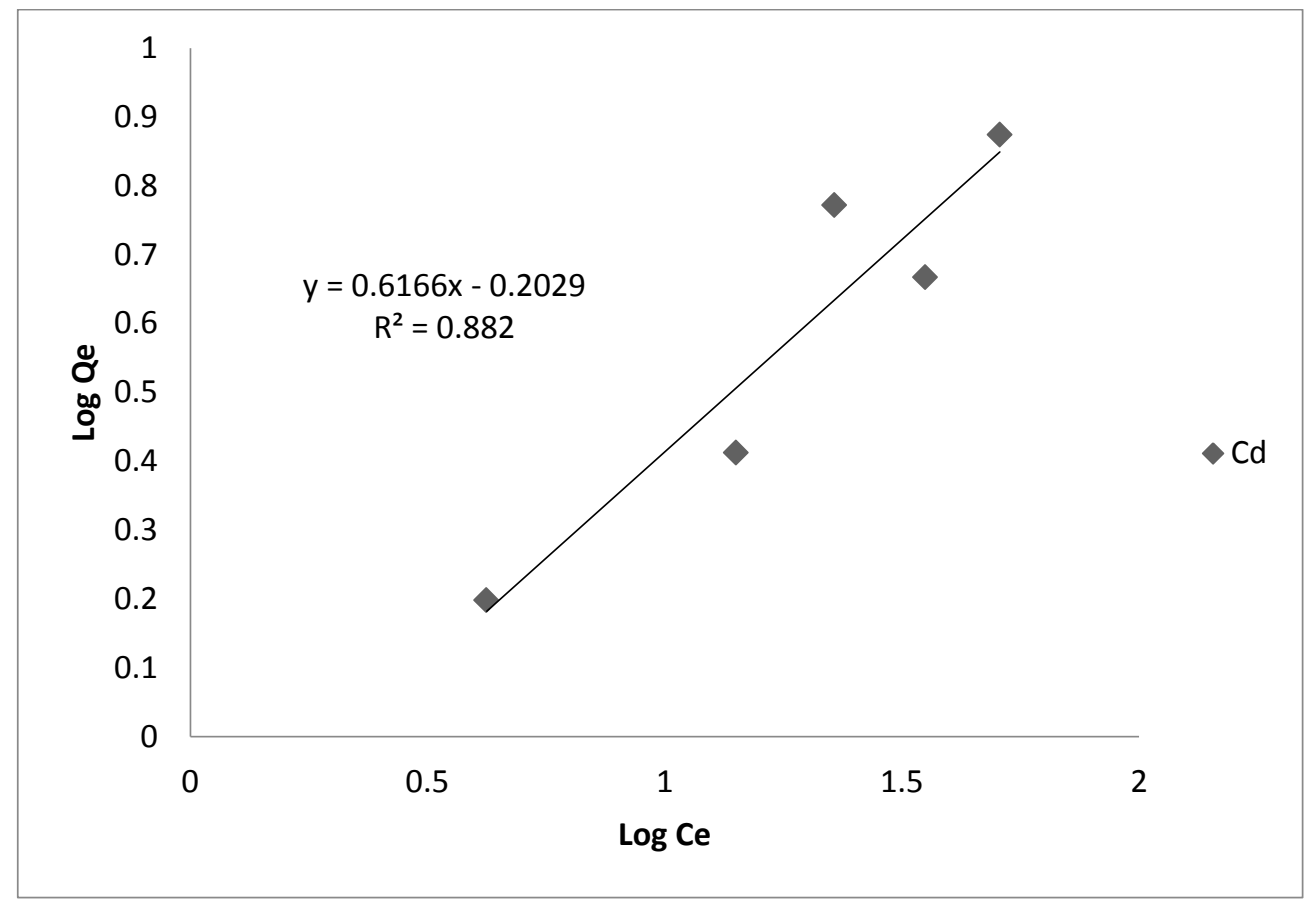

Figure 6. Linearized Freundlich Isotherms for Adsorption of Cd onto Activated Rice husk adsorbent $($ dose $=0.5-\mathrm{g} / 50 \mathrm{~mL})$

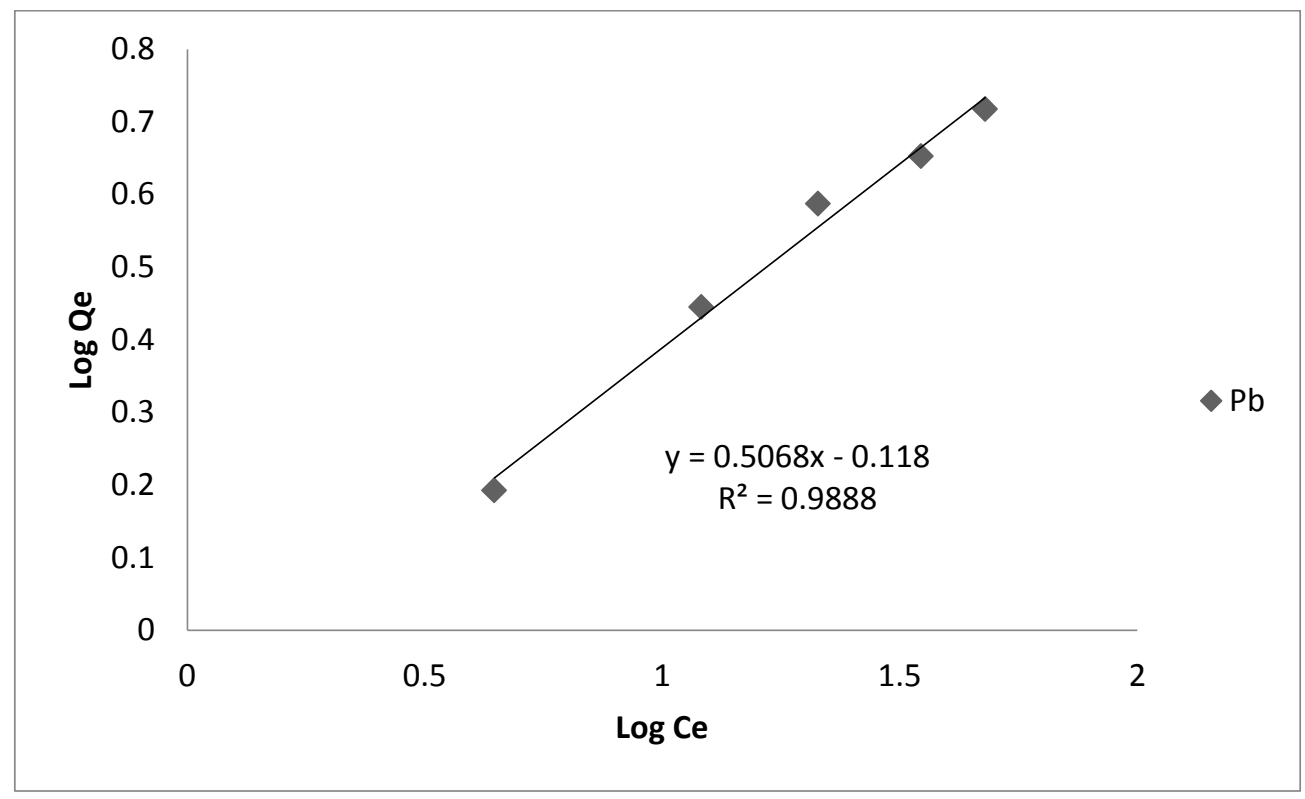

Figure 7. Linearized Freundlich Isotherms for Adsorption of Pb onto Unactivated Rice husk adsorbent $(\mathbf{d o s e}=\mathbf{0 . 5}-\mathrm{g} / \mathbf{5 0}$ $\mathrm{mL}$ ) 


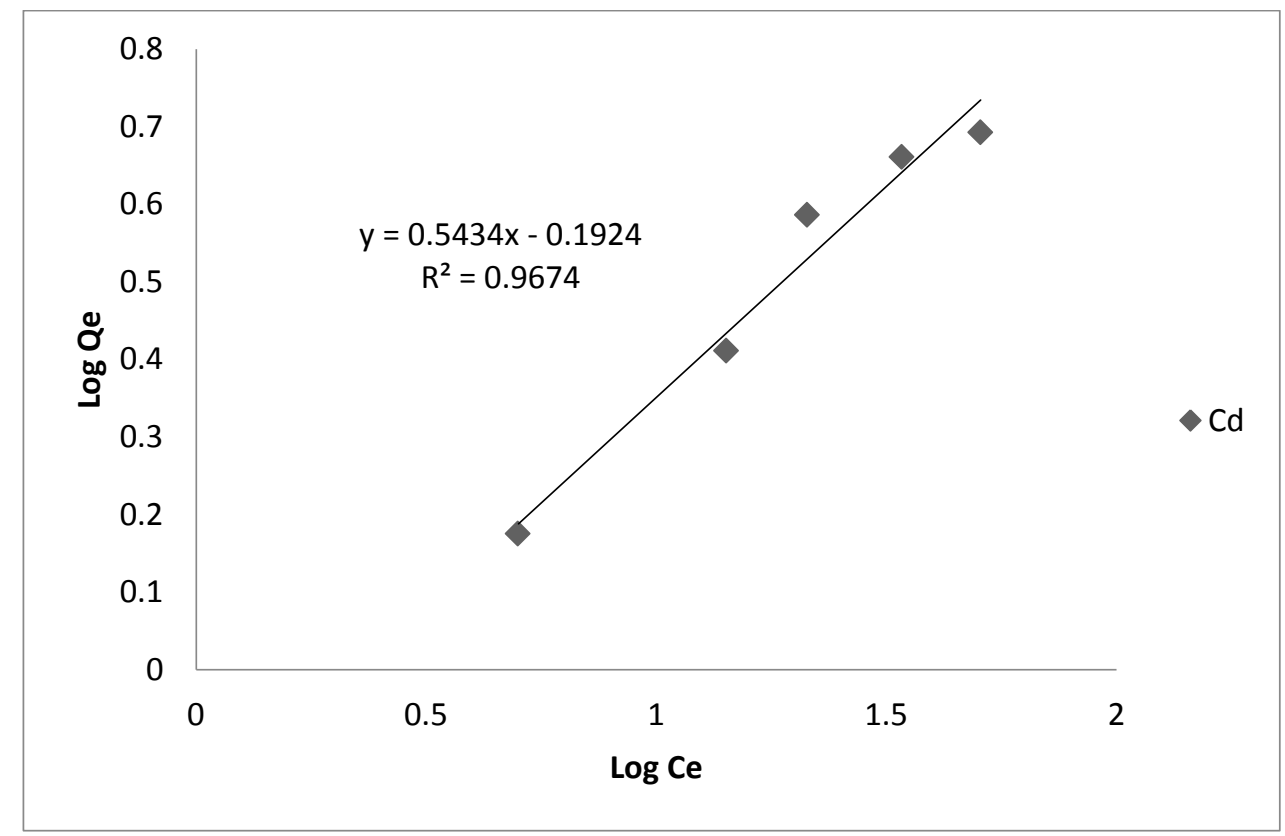

Figure 8. Linearized Freundlich Isotherms for Adsorption of Cd onto Unactivated Rice husk adsorbent $($ dose $=0.5-\mathrm{g} / 50$ $\mathbf{m L})$

Table 1. Isotherm Parameters for $\mathrm{Pb}$ and $\mathrm{Cd}$ Adsorption onto Activated rice husk adsorbent ARHC and unactivated rice husk adsorbent URHC

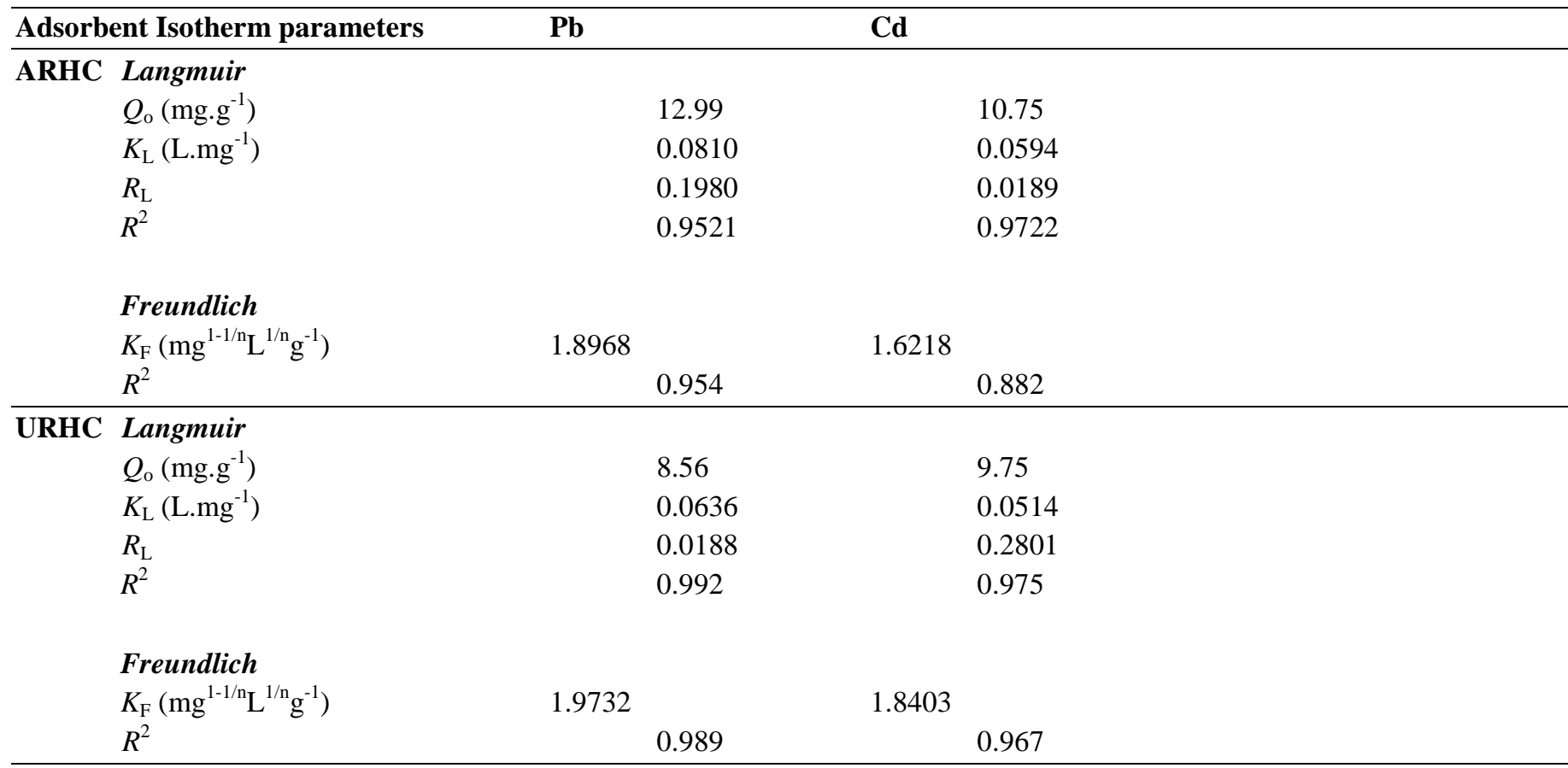

\section{DISCUSSIONS}

\subsection{Effect of Initial Solution $\mathrm{pH}$ on $\mathrm{Pb}$ and $\mathrm{Cd}$ Adsorption}

The result from figure 1 shows the effect of $\mathrm{pH}$ on the adsorption of $\mathrm{Pb}$ and $\mathrm{Cd}$. In this study, the effect of solution $\mathrm{pH}$ was investigated over the $\mathrm{pH}$ ranges of 3,5, 7, 9 and 11 with the initial concentration of $\mathrm{Pb}$ and $\mathrm{Cd}$ fixed at $100 \mathrm{mg} / \mathrm{L}$. The result shows that the adsorbed amount of $\mathrm{Pb}$ and $\mathrm{Cd}$ decreases with increasing $\mathrm{pH}$ value for activated rice husk adsorbent (ARHC), while amount adsorbed tend to increase with increase in $\mathrm{pH}$ for unactivated rice husk adsorbent (URHC). The highest uptakes for (ARHC) $\mathrm{pH} 3$ for both metals $\mathrm{Pb}$ and $\mathrm{Cd}$. For (URHC) highest uptakes were recorded at $\mathrm{pH} 7$ and $\mathrm{pH} 9$, respectively. 


\subsection{Effect of Adsorbent Dose on $\mathrm{Pb}$ and $\mathrm{Cd}$ Adsorption}

This parameter determines the capacity of the adsorbent for a given $\mathrm{Pb}$ and $\mathrm{Cd}$ concentration and adsorbate-adsorbent equilibrium of the system as determined. (Figure 3 and 4) shows the plot of the $\mathrm{Pb}$ and Cd uptake against the quantity of adsorbents ARHC and URHC. The metal ions uptake per unit mass decreased with the increase in adsorbent dosage for both adsorbents. (Ahmednaet al., 2000.Sirhari and Das, 2009; Moyoet al., 2012) the reason for this trend may be attributed to the fact that at high sorbent dosages, the available $\mathrm{Pb}$ and $\mathrm{Cd}$ molecules are not able to cover all the exchangeable sites on the biosorbent, resulting in low $\mathrm{Pb}$ and $\mathrm{Cd}$ uptake. Maximum uptake was observed at dosage of $0.5-\mathrm{g}$.

\subsection{Adsorption Isotherm Models}

There are several models that have been reported in literature to show equilibrium relationships between sorbent and sorbate. The Langmuir and Freundlich models are the most frequently employed models. In this work, both models were used to describe the relationship between the amount of lead and cadmium and their equilibrium concentrations. Isothermal data for the adsorption of $\mathrm{Pb}$ and $\mathrm{Cd}$ from aqueous phase onto the different adsorbents were fitted into the linearized forms of the Langmuir (1) models as stated earlier.

where, $C_{e}$ is the equilibrium concentration of the adsorbate, $Q_{e}$ is the amount adsorbed at equilibrium $\left(\mathrm{mg} \mathrm{g}^{-1}\right), Q_{o}\left(\mathrm{mg} \mathrm{g}^{-1}\right)$ and $K_{L}$ $\left(\mathrm{L} \mathrm{mg}{ }^{-1}\right)$ are the Langmuir constants related to monolayer adsorption capacity and affinity of adsorbent towards adsorbate, respectively. Langmuir isotherm constants were determined from the plots of $C e / Q e$ versus $C_{e}$ and slope $1 / Q_{o}$ was obtained from Figure 5, 6, 7 and Figure 8, respectively indicating that the adsorption of $\mathrm{Pb}$ and $\mathrm{Cd}$ onto ARHC and URHC follows the Langmuir isotherm. The Langmuir constant $k_{\mathrm{L}}$ and ' $Q_{o}$ ' were calculated from this isotherm and their values given in (Table 1).

Where $Q_{e}$ is the amount absorbed at equilibrium $\left(\mathrm{mg} \mathrm{g}^{-1}\right), C_{\mathrm{e}}$ equilibrium concentration of $\mathrm{Pb}$ and $\mathrm{Cd}$, and $k_{F}$ and $n_{F}$ are Freundlich constant. And $k_{F}\left(\mathrm{mg}^{1-1 / n} \mathrm{~L}^{1 / \mathrm{n}} \mathrm{g}^{-1}\right)$ is the adsorption capacity of the adsorbent. $k_{F}$ can be define as the adsorption or distribution coefficient and represent the quantity of $\mathrm{Pb}$ and $\mathrm{Cd}$ adsorbed onto activated rice husk adsorbent ARHC and unactivated rice husk adsorbent URHC for a unit equilibrium concentration. The values of $K_{F}$ and $1 / n_{F}$ were determined from the intercept and, linear plot of $\log Q e$ versus $\log C_{e}$ respectively.

The linearized Freundlich adsorption isotherms of ARHC and URHC for lead and cadmium adsorption are shown in Figures 9 12 respectively. The Langmuir and Freundlich constants are also shown in (Table 1). The higher regression values showed that the equilibrium data for the adsorption of $\mathrm{Pb}$ and $\mathrm{Cd}$ fitted well to both the Langmuir and Freundlich isotherms in the studied concentration ranges. Based on the regression coefficients $\left(R^{2}\right)$, the equilibrium data was slightly better fitted in Langmuir adsorption isotherm for both ARHC and URHC than the Freundlich equation (Table 1). The higher values of $K_{F}$, the Freundlich constant for ARHC showed easy uptake of $\mathrm{Pb}$ and $\mathrm{Cd}$ from aqueous solution than the URHC (Rengarajet al., 2002).

Also the higher values of $n_{F}$ reflects the intensity of adsorption hence signifies that the surfaces of biosorbent is heterogeneous in nature and high enough for effective separation (Khalid et al., 2000). In this study, and above all the equilibrium data were fitted well by the Freundlich and Langmuir isotherms, where the data were slightly better fitted by the Langmuir isotherm in terms of regression values and separation factors.

\subsection{Effect of Contact Time of $\mathrm{Pb}$ and $\mathrm{Cd}$ Adsorption onto Activated Rice Husk Adsorbent (ARHC) and Unactivated Rice Husk Adsorbent (URHC)}

The characteristics of Rice husk adsorbents and its available sites affected the time needed to reach equilibrium. The experimental results for determination of equilibrium time are given in (Figures 6 and 7) and it is obviously seen that adsorption capacity increased with increasing contact time $\left(Q_{\mathrm{t}}\right)$. Large amounts of $\mathrm{Pb}$ and $\mathrm{Cd}$ were removed in the first 90 min and equilibrium was reached at $120 \mathrm{~min}$, after the equilibrium point, adsorption uptake was not increased significantly, (Guang-qianet al., 2012; Bandoseet al., 2003)

\subsection{Adsorption kinetics studies}

The experimental data for the adsorption of $\mathrm{Pb}$ and $\mathrm{Cd}$ as a function of contact time were fitted into the Lagergren pseudo firstorder (Equation 4), Blanchard pseudo second-order kinetic models (Equation 5). In order to investigate the adsorption processes of $\mathrm{Pb}$ and $\mathrm{Cd}$ onto ARHC and URHC, kinetic analyses were usually conducted using equations 4 and 5 as indicated earlier. were $Q_{\mathrm{e}}\left(\mathrm{mg} \mathrm{g}^{-1}\right)$ is the calculated equilibrium amount of $\mathrm{Pb}$ and $\mathrm{Cd}$ adsorbed onto ARHC and URHC using this two models, $Q_{\mathrm{t}}$ $\left(\mathrm{mg} \mathrm{g}^{-1}\right)$ is the amount of $\mathrm{Pb}$ and $\mathrm{Cd}$ adsorbed onto ARHC and URHC at time $t(\mathrm{~min}) ; k_{l}\left(\min ^{-1}\right)$ is the rate constant of pseudo-first order model; and $k_{2}$ (mg.min) is the rate constant of pseudo-second order model. The values of $k_{1}$ and $k_{2}$ were calculated from the plots of $1 \mathrm{n}\left(Q_{\mathrm{e}}-Q_{\mathrm{t}}\right)$ versus $t$ and $t / \mathrm{Q}$ versus $t . k_{1}$ and $k_{2}$ were determined from the slope and intercept of the plots. If second-order model is applicable, the plots of $t / Q$ versus $t$ should show a linear relationship. From the subsequent experiment, the pseudosecond order model was suitable to describe the adsorption kinetics of $\mathrm{Pb}$ and $\mathrm{Cd}$ onto ARHC and URHC. 


\subsection{CONCLUSIONS}

This study investigated the adsorption capacities of $\mathrm{Pb}$ and $\mathrm{Cd}$ onto ARHC and URHC. The effect of various parameters such as $\mathrm{pH}$, adsorbent dose, adsorbent concentration, and contact time on removal of $\mathrm{Pb}$ and $\mathrm{Cd}$ by ARHC and URHC were also examined. Adsorption capacity decreases with increase in solution $\mathrm{pHs}$. The equilibrium data fitted with Langmuir and Freundlich isotherm models, but best fitted with Langmuir isotherm model. The adsorption kinetics for this study was best described by the pseudo-second order kinetics. Significant removal of $\mathrm{Pb}$ and $\mathrm{Cd}$ was found under acidic conditions for adsorbent ARHC and alkaline for URHC i.e. a higher removal (E\% 80.435) was obtained with ARHC. Also metals removal were found to be directly proportional to increasing $\mathrm{Pb}$ and $\mathrm{Cd}$ concentration up to $80 \mathrm{mg} / \mathrm{L}$, after which equilibrium point were attained at $100 \mathrm{mg} / \mathrm{L}$. The processes were more feasible and spontaneous for adsorbents ARHC than URHC. Finally, it can be concluded that ARHC is a better adsorbent than URHC for the removal of $\mathrm{Pb}$ and $\mathrm{Cd}$ from their aqueous phase solution.

\section{ACKNOWLEDGEMENT}

We would like to specially acknowledge Tertiary Education Trust Fund (TETFUND) as the sponsors of this research work.

\section{REFERENCES}

1. Hodson, M.E (2013). "Effects of heavy metals and metalloids on soil organisms," in Heavy metals in soils, ed: Springer, pp. 141-160.

2. Chen, S.Y. and Huang, Q. Y.(2013) "Heavy Metals Recovery From Wastewater Sludge Of Printed Circuit Board Industry By Thermophilic Bioleaching Process," Journal of Chemical Technology and Biotechnology.

3. Sadiq, A.G. (2010) Zamfara releases 240 million over mining death" Daily Trust, Jun 7. P2

4. Mamdouh, S. Masoud, A. Wagdi, M. El-Saraf, B. Abdel - Halim, A. M. Alaa, E. Ali, C. Essam, A. Mohamed, C. Hamad, M.I. (2016) 'Rice husk and activated carbon for waste water treatment of El-Mex Bay, Alexandria Coast, Egypt" Arabian Journal of Chemistry 9, S1590-S1596.

5. Sandhyrianri, V. and Das, A. (2009).Adsorption of Phenol from Aqueous Media by an Agro Waste (Hemidesmusindicus) Based Activated Carbon.Applied Ecology and Environmental Research. 7 (1): 13-23

6. American Water Works Association (AWWA) (1991).Standards for Granular Activated Carbon, NSI/AWWA B604-90, Denver Co. 117 -124.

7. Muhammed A. Ansari R. (2004). Adsorption of heavy metals from aqueous solutions using activated carbon. Arab World Water Journal (AWW), 2, 10-12.

8. Asiagwu A.K. Owamah, H.I. and Illoh, V.O. (2012). Kinetic Thermodynamic Model for the Removal of Amino Phenol (dye) from Aqueous Solution using Groundnut Arachis hypogea Shells as the Biomass. Journal of Advances in Applied Science Research. 3(4): 2257 - 2265.

9. Bandosz R.R. Losso J.N. Marshall W.E. Rao R.M. Portier R.J. (2003). Adsorption of volatile organic compounds by pecan shell- and almond shell-based granular activated carbons.Bioresource. Technology, 90(2), 175-184

10. Ansari R. NikravanShalmani, S. (2005). Adsorption of some phenolic compounds from aqueous solutions using activated carbon. International Journal of Chemistry, 15(2), 95-99.

11. El-Shafey, E. Cox, M. Pichugin, A.A. Appleton, Q. (2002). Application of a carbon sorbent for the removal of cadmium and other heavy metal ions from aqueous solution, Journal of Chemical Technology and Biotechnology, 77(4), 429-436.

12. Wuana, R.A. Nnamonu, L, A, and Idoko, J.O. (2015). Sorptive removal of phenol from aqueous solution by Ammonium Chloride-Treated and Carbonized Moringaoleifera seed Shells, International Journal of Science and research, 4(6): 594 -602 .

13. Wuana, R.A. Okieimen, F.E. Adejo, S.O. and Mbasugh, P.A. (2009).Single and Competitive Aqueous Phase Adsorption of Calcium and Magnesium ions onto Rice Husk Carbon.Journal of Chemical Society of Nigeria. 34 (1) : 97 109. 